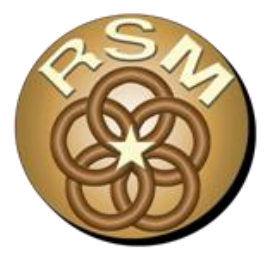

\title{
Geochemical Fingerprinting of Sediment Sources Associated with Deposition in the Calcasieu Ship Channel
}

by David Perkey, Anthony Priestas, Brandon Boyd, Jeff Corbino, and Lee Moores

PURPOSE: This Regional Sediment Management Technical Note (RSM-TN) demonstrates how geochemical fingerprinting techniques were used to distinguish probable sediment sources to the Calcasieu Ship Channel (CSC). These methods were applied to sediment samples collected from suspected source areas identified in past sediment budget studies. The techniques can be used by managers and stakeholders to make more informed decisions on best practices for managing sediment and mitigating sediment deposition within the channel.

\section{INTRODUCTION}

Motivation. Managing sediment within the nation's navigable waterways is one of the primary missions of the US Army Corps of Engineers (USACE). As such, understanding sediment transport and deposition processes is an important aspect of many USACE projects, particularly when it comes to the maintenance of navigation channels. To maintain the nation's ports and channels, the USACE expends approximately $\$ 1.4$ billion annually and removes more than 140 million $\mathrm{m}^{3 * \dagger}$ of material in dredging activities (USACE 2016). Discerning the sediment sources that lead to infilling is therefore a crucial component to effectively managing sediment within the nation's waterways. Identification of these sediment sources could potentially allow USACE to reduce dredging volumes through engineering or other mitigation actions to minimize sedimentation when possible. Geochemical fingerprinting is a well-established method for distinguishing among sediment sources (Collins and Walling 2002; Collins et al. 2010; Papanicolaou et al. 2003; Gireeshkumar et al. 2013; Perkey et al. 2017). This technique relies on coupling the geochemical properties between the sediments transported into an area of interest and those of their suspected sources. In this study, these techniques were applied to sediments within the $\mathrm{CSC}$ and in the immediately adjacent environments.

Background. The CSC is a federal deep-draft navigation channel located in Southwest Louisiana, connecting the Port of Lake Charles (one of the largest ports in the nation by tonnage of cargo) to the Gulf of Mexico (Figure 1). To maintain the navigation channel between river miles

\footnotetext{
* For a full list of the spelled-out forms of the units of measure used in this document, please refer to US Government Publishing Office Style Manual, 31st ed. (Washington, DC: US Government Publishing Office 2016), 248-52, https://www.govinfo.gov/content/pkg/GPO-STYLEMANUAL-2016/pdf/GPO-STYLEMANUAL-2016.pdf. $\dagger$ For a full list of the unit conversions used in this document, please refer to US Government Publishing Office Style Manual, 31st ed. (Washington, DC: US Government Publishing Office 2016), 345-7, https://www.govinfo.gov/content/pkg/GPO-STYLEMANUAL-2016/pdf/GPO-STYLEMANUAL-2016.pdf.
} 
(RM) 5 and 34 (Figure 1), the USACE, New Orleans District, annually dredges an estimated 3 to 4 million $\mathrm{m}^{3}$ of sediment at considerable costs.

Prior research conducted by the US Army Engineer Research and Development Center (ERDC) and the Water Institute of the Gulf attempted to identify the potential sediment sources and their potential transport pathways. The following briefly summarizes their main findings. A bank line erosion assessment conducted by Fischenich (2004) indicated that approximately $20 \%$ of the annual dredge volume of the CSC could be attributed to contributions from the discharge of the Calcasieu River and erosion of the adjacent channel banklines. These potential sources accounted for approximately $6 \%$ and $14 \%$ of the dredging volume, respectively. Additionally, Fischenich (2004) reported that the contribution from bankline erosion is localized to the reach south of the Gulf Intracoastal Waterway (GIWW).

A follow-on study conducted by Brown* sought to identify and quantify additional sediment sources that would account for the remaining $80 \%$ of sediment deposited within the CSC. Sediment transport and deposition were simulated using the Adaptive Hydraulics (AdH) model. Depositional patterns derived from the modeling results suggested that much of the Calcasieu River's sediment yield might be sequestered in Lake Charles and other upstream waterways prior to reaching the CSC. Conversely, simulations of marine sediment transport from tidal pumping was shown to deposit in concentrated areas of Lake Calcasieu, just east of the CSC near RM 5-7. A revised sediment budget analysis suggested that approximately $40 \%$ of channel shoals originated from eroded channel banklines and wetlands within the Calcasieu Basin; 20\% originated from marine sediments carried in on the tides; and 5\% originated from the discharge of the Calcasieu River above RM 34. While this new budget reduced the unaccounted volume of annually dredged CSC sediment to $35 \%$, Brown recommended that a follow-on sediment provenance study be conducted to potentially reduce the indeterminate sources of sediment to the CSC and evaluate his most recent sediment budget.

A separate sediment budget study for the Calcasieu system was conducted by the Water Institute of the Gulf (WIG 2019). The study was based on data obtained during an extensive 1-year field campaign in conjunction with Delft3D modeling simulations. In contrast to Brown's ${ }^{1}$ study, the WIG investigation concluded that sediments derived from Lake Calcasieu and its adjacent bayous and marshes accounted for only $1 \%-5 \%$ of the total dredging volume during average meteorological conditions, though could be significantly higher (up to 20\%) during tropical storm conditions. Additionally, their measurements and simulations of sediment fluxes through the CSC suggested that Lake Calcasieu might alternate as a sediment source or sink depending on specific storm conditions (WIG 2019).

Although the results from the aforementioned studies provided much insight into the sediment budgets and dynamics of the system, sediment sources to the CSC could not be completely verified. Consequently, this report highlights the geochemical fingerprinting study and results to address the recommendations made by Brown ${ }^{1}$. It also demonstrates how these types of studies can be utilized by resource managers and stakeholders to evaluate differences in reported sediment budgets to make informed decisions on sediment processes within their area of interest.

* Brown, Gary. In preparation. Investigation of Sources of Sediment Associated with Deposition in the Calcasieu Ship Channel. FY18 RSM project report for US Army Engineer District, New Orleans. 


\section{METHODS}

Sample Collection. To help identify the origin of shoaling sediments within the CSC, a series of six geomorphological sediment classifications were used. Five of the classifications included the most probable sources of infilling sediment from which sediment samples were collected. These were (1) Calcasieu River bottom sediments from outside the navigation channel and upstream of the Gulf Intracoastal Waterway (GIWW) at RM $22(\mathrm{~N}=4)$; (2) the banks of the Calcasieu shipping channel ( $\mathrm{N}=13)$; (3) the shorelines of Calcasieu Lake ( $\mathrm{N}=14)$; (4) bottom sediment of Calcasieu Lake $(\mathrm{N}=17)$; and (5) offshore sediment delivered through tidal exchange $(\mathrm{N}=6)$. The sixth classification of sediment was defined as the bottom sediment from within the CSC $(\mathrm{N}=15)$. In all, 69 samples were collected and analyzed to characterize the sediment properties of these specific classifications. Sample locations and classifications are provided in Figure 1.

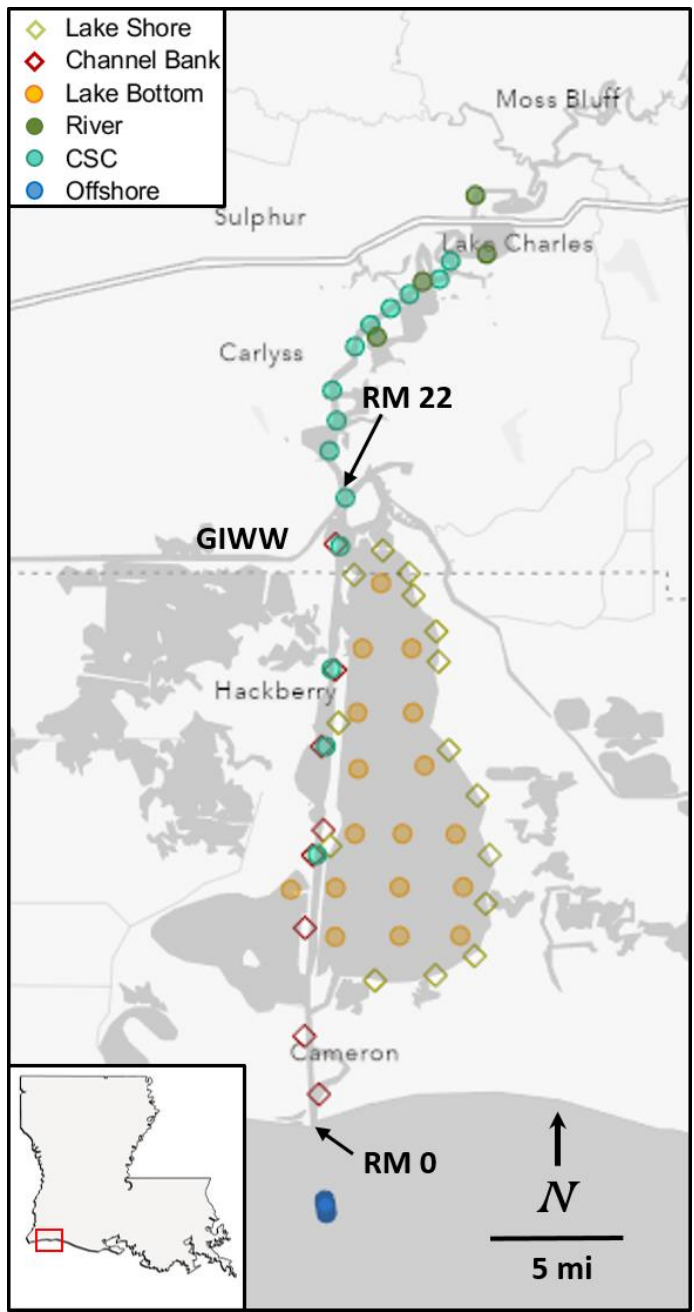

Figure 1. Map of sample locations. Diamonds indicate samples collected from the bank lines while circles indicate samples collected from the channel bottom. 
Sample collection occurred in two phases. First, inshore samples from the CSC and its adjacent waters and bank lines were collected February 28 through March 2 of 2019. Bottom sediment samples were obtained with either a 3 in. diameter drag pipe sampler or a stainless steel scoop sampler. Sediment samples obtained from the bank lines of the channel and lake were collected with a spade or garden shovel. Approximately 1-2 L of sediment were collected from each station and placed in sterile whirl-pak bags. All sampling equipment contacting the sediment was rinsed with site water prior to subsequent sampling at each location. Samples were transported to the ERDC where they were stored in a $4^{\circ} \mathrm{C}$ refrigerator until processed.

The second sampling phase occurred in April 2019 when maintenance dredging was being performed on a portion of the offshore channel bar. During these dredging operations, sediment samples were collected from six dredge loads. To obtain these samples, a 5 gal bucket was filled from the sediment discharge pipe coming into the hopper. After settling, overlying water was decanted, and the remaining bucket contents were mixed. A 1-2 L sediment sample was then poured into sterile whirl-pak bags. All sediment samples were stored in a cooler and shipped on wet ice to the ERDC, where they were transferred and held in a $4{ }^{\circ} \mathrm{C}$ refrigerator until processing in the lab.

Sample Processing. All sediment samples were processed at the ERDC Coastal and Hydraulics Laboratory. To prepare the samples, they were first wet screened through a number $5(4 \mathrm{~mm})$ sieve with distilled water to remove large organic matter and other debris. The screened material was retained in $6 \mathrm{~L}$ polycarbonate containers and placed in a $50^{\circ} \mathrm{C}$ drying oven for $24-48 \mathrm{hr}$. Any remaining supernatant water was removed using a peristaltic pump. Samples were thoroughly mixed and subsampled for grain size distribution and geochemical analyses.

Grain Size Analysis. Grain size distributions were obtained using a Malvern Mastersizer 2000 laser diffraction particle sizer, which measures particle diameters in the range of 0.02 to 2000 $\mu \mathrm{m}$. Specimens of 1-2 g were treated overnight with a $40 \mathrm{~g} / \mathrm{L}$ solution of sodium metaphosphate to disperse cohesive particles. Additionally, samples were passed through a $1 \mathrm{~mm}$ sieve over the instrument's reservoir to remove any residual macro organics, then sonicated for $60 \mathrm{sec}$ prior to measurement.

Loss on Ignition (LOI) Analyses. The total volatile organic content of the sediment samples was determined by LOI as described in ASTM D2974 (2014) method C. Following recommendations reported by Schumacher (2002) and Salehi et al. (2011), the combustion temperature was reduced from the ASTM guidance of $440^{\circ} \mathrm{C}$ to $360^{\circ} \mathrm{C}$.

Geochemical Analyses. Subsamples of sediment for geochemical analyses were placed in ceramic bowls and dried in a $50^{\circ} \mathrm{C}$ oven. After drying, approximately $50 \mathrm{~g}$ of sample were pulverized until they passed through a number $60(0.25 \mathrm{~mm})$ sieve. Aliquots of the powder were then set aside for the following analyses: X-ray fluorescence (XRF), soil nutrients, and stable carbon $\left(\delta^{13} \mathrm{C}\right)$ and nitrogen $\left(\delta^{15} \mathrm{~N}\right)$ isotopes.

XRF. Elemental compositions were determined through XRF techniques using a Thermo Fisher XL3 Analyzer in "Soil Mode." Powdered samples were packed into $32 \mathrm{~mm}$ sample cups and analyzed with all three of the instrument's excitation filters enabled. Data were collected for $60 \mathrm{sec}$ at each filter setting. Further detail on sample cup preparation, sampling procedures, and analysis techniques can be found in the Thermo Fisher XL3 manual (2010). 
Soil nutrients. Routine soil nutrient analyses were performed at the Louisiana State University (LSU) Agricultural Center soil laboratory. The elemental content of phosphorous, potassium, calcium, magnesium, sodium, sulfur, copper, and zinc ( $\mathrm{P}, \mathrm{K}, \mathrm{Ca}, \mathrm{Mg}, \mathrm{Na}, \mathrm{S}, \mathrm{Cu}, \mathrm{Zn}$ ) was obtained through Inductively Coupled Plasma mass spectrometry techniques (Mehlich 1984).

Carbon and nitrogen stable isotopes. Sediment samples were shipped to the LSU Stable Isotope Ecology Laboratory for carbon and nitrogen analysis. Percent total nitrogen $(\mathrm{N})$ and organic carbon content was measured with a Costech ECS4010 elemental analyzer. Out-flowing gas was analyzed for $\delta^{13} \mathrm{C}$ and $\delta^{15} \mathrm{~N}$ with a Thermo-Fisher Delta Plus XP stable isotope ratio mass spectrometer. The delta values are the isotope ratios of ${ }^{13} \mathrm{C} /{ }^{12} \mathrm{C}$ and ${ }^{15} \mathrm{~N} /{ }^{14} \mathrm{~N}$ reported in \%o relative to the standard Vienna Pee Dee Belemnite and atmospheric $\mathrm{N}_{2}$ (AIR) for $\delta^{13} \mathrm{C}$ and $\delta^{15} \mathrm{~N}$, respectively.

Data Analysis. Data analysis was performed using the built-in function prcomp within the $\mathrm{R}$ ( $\mathrm{R}$ Core Team 2019) statistics software environment, and the output was visualized using the Factoextra package (Kassambara and Mundt 2017). Two multivariate statistical procedures were used for data reduction-Principal Components Analysis (PCA) and Cluster Analysis. These common techniques are used to reveal informative relationships and patterns in multivariate data sets.

Principal components analysis (PCA). Prior to performing the PCA calculations, variables were first standardized by their z-scores. Standardization is necessary for variables with widely varying ranges and different units of measure (Johnson and Wichern 2007).

In a PCA, the complexity of the data is reduced by using linear correlations between user-defined groups of variables to develop new, uncorrelated variables (principal components) that can better explain variance within the data. The aim is that the majority of variance in complex data can be summarized with only the first two or three principal components (PC). From a data exploration perspective, similar groups of observations will plot closer to each other in PC space.

K-Means cluster analysis. To evaluate data clustering based on statistical similarity, a nonhierarchical K-Means procedure was also used on the standardized data set. Whereas data groups were user defined in the PCA, cluster analysis attempts to find groups within data sets that are unknown and undefined without any a priori assumptions. Geometrically, groups are partitioned by Thiessen polygons, meaning observations within groups are more similar to each other than observations outside the groups based on pairwise dissimilarities. Here, the optimal number of clusters was determined using the within-cluster sum of squares (WSS) method, which is the number of clusters that minimizes the total WSS (Everitt 2005). Since the clustering algorithm relies on the seeding of randomized centroid positions, the procedure was run five times with different seeds to observe any changes to cluster positions, sizes, or explained variance.

Selection of variables. Although PCA implicitly selects variables that capture the most variance, some researchers argue that the ratio of observations to variables should be approximately 3 to 1 for stability and reliability of multivariate analyses (King and Jackson 1999). In this study, 18 of the 63 measured variables were selected for this analysis (Table 1). The criteria for selection was based on a Pearson correlation ( $r$ ) threshold of $\geq 0.65$ between three or more covariates.

\begin{tabular}{|c|c|c|c|c|c|c|c|c||}
\hline \multicolumn{7}{||c|}{ Table 1. Variables used in data analysis. } \\
\hline \hline Fines $(<63 \mu \mathrm{m})$ & $\mathrm{Cr}$ & $\mathrm{Zr}$ & $\mathrm{Rb}$ & $\mathrm{Th}$ & $\mathrm{Pb}$ & $\mathrm{Zn}$ & $\mathrm{Fe}$ & $\mathrm{Mn}$ \\
\hline $\mathrm{LOI}$ & $\mathrm{V}$ & $\mathrm{Ti}$ & $\mathrm{Mg}$ & $\mathrm{Cs}$ & $\mathrm{Te}$ & $\mathrm{Sb}$ & $\mathrm{Sn}$ & $\mathrm{N}$ \\
\hline
\end{tabular}




\section{RESULTS}

PCA. Results from the PCA showed that the preponderance of the variance (73\%) was explained using only the first two components (PC1 52.2\% and PC2 20.7\%). Thus, the dominant relationships between the observations, PC scores, and PC loadings can be displayed in twodimensional space, as shown graphically in Figure 2. Although there is significant scatter in the data, Figure 2 shows that the observations are largely separable by the origin of the PC1 dimension. With this interpretation, observations with positive $\mathrm{PC} 1$ values are predominantly river, CSC, and offshore samples; these samples are characterized by higher loadings in elements such as $\mathrm{Mn}, \mathrm{Mg}$, $\mathrm{Fe}, \mathrm{Zn}, \mathrm{Rb}, \mathrm{Cr}, \mathrm{N}$, and fines, and strongly influence the variance explained in PC1 (longer vectors indicate variables with stronger influence on the model). Conversely, observations with negative PC1 values are comprised of lake-bottom, lake-shore, and CSC bankline samples; these samples are relatively lighter in the elements of the first cluster but are heavier in zircon.

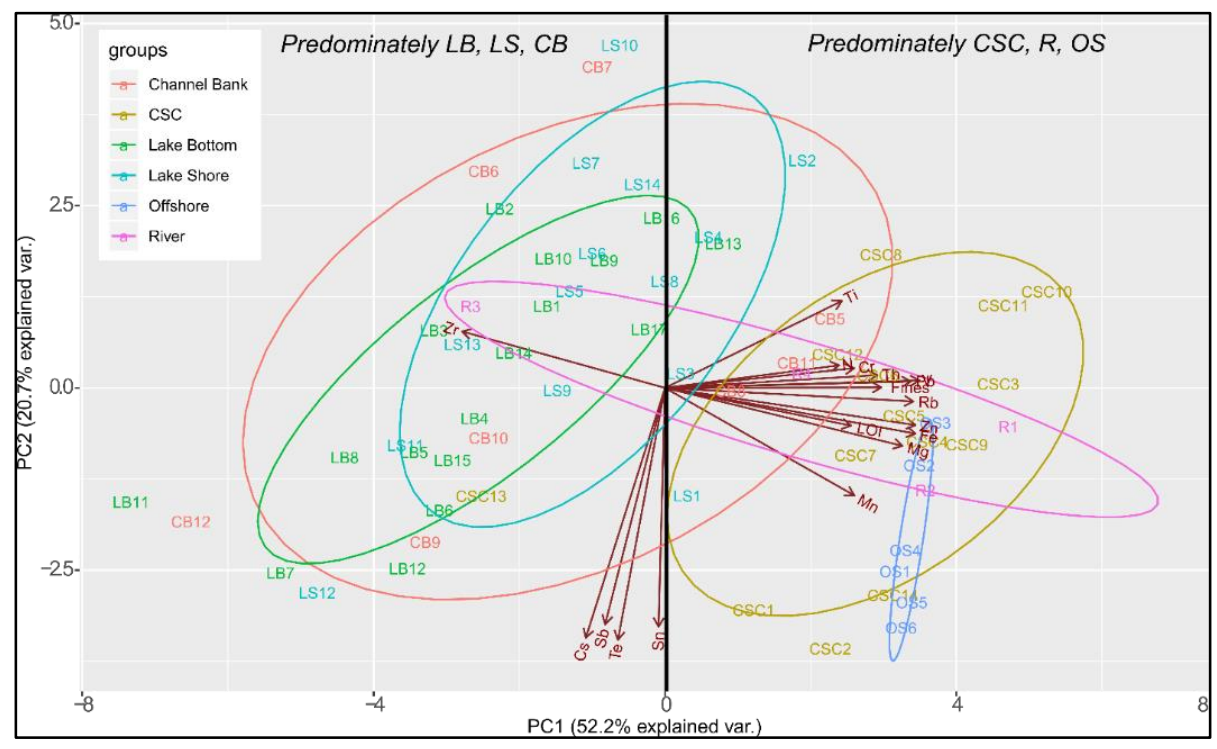

Figure 2. Bivariate plot of the first two PCs shown with ellipses indicating one standard deviation for different groups. The percent variation explained in each PC is labeled along the axes. Arrows represent the PC loadings, which indicate the weight each has on the PCs. The data are partitioned into two assemblages along PC1; samples with negative values are composed mostly of lake-bed, lake-shore, and CSC channel bank samples while positive values consists of mostly CSC, river, and offshore samples.

Certain sample groups are shown to cluster more tightly than others, which is a reflection of the similarities in their elemental characteristics. For example, the close grouping of the offshore samples indicates they are relatively homogeneous, showing little variability in PC1 and some variability in PC2. In contrast, samples that plot farther away from each other are more dissimilar. Samples from the CSC bankline (CB) are shown to have substantial variability and overlap in both PC dimensions, which may reflect the variability in the depositional environments from which they were collected.

K-Means Cluster Analysis. WSS techniques identified three clusters as the optimal number of partitions for the data as shown in the cluster plot of Figure 3. Note that the observations are plotted in the same PC space as Figure 2. (As previously explained, the primary difference in K-Means is 
that observations are not pre-assigned to a group by the user). To evaluate the quality of the clustering resulting from randomized initial centroids positions, model runs were repeated with different seeding values, which did not significantly alter the clustering results.

Similar to the PCA results, river, CSC, and offshore samples grouped in a single cluster (cluster 1) whereas clusters 2 and 3 largely consist of Lake Calcasieu samples (lake-bottom and lake-shore) and the $\mathrm{CB}$ material. Measures of the total dispersion (from the sums of squares values) within and between clusters (WSS and between sum of squares [BTSS]) is provided in Table 2. Smaller values of WSS indicate greater homogeneity, and therefore, tighter clustering. The ratio "Between SS/Total SS" provides a measure of the goodness of fit of the clusters; for three clusters, the variance explained is $55.8 \%$ (Table 2). Thus, the observations within Cluster 1, which contain samples from the CSC, river, and offshore, display the most homogeneity relative to Clusters 2 and 3. Additionally, the Euclidean distances between cluster centroids provides a measure of their relative differences. Thus, the clusters appear to be meaningfully dissimilar to each other.

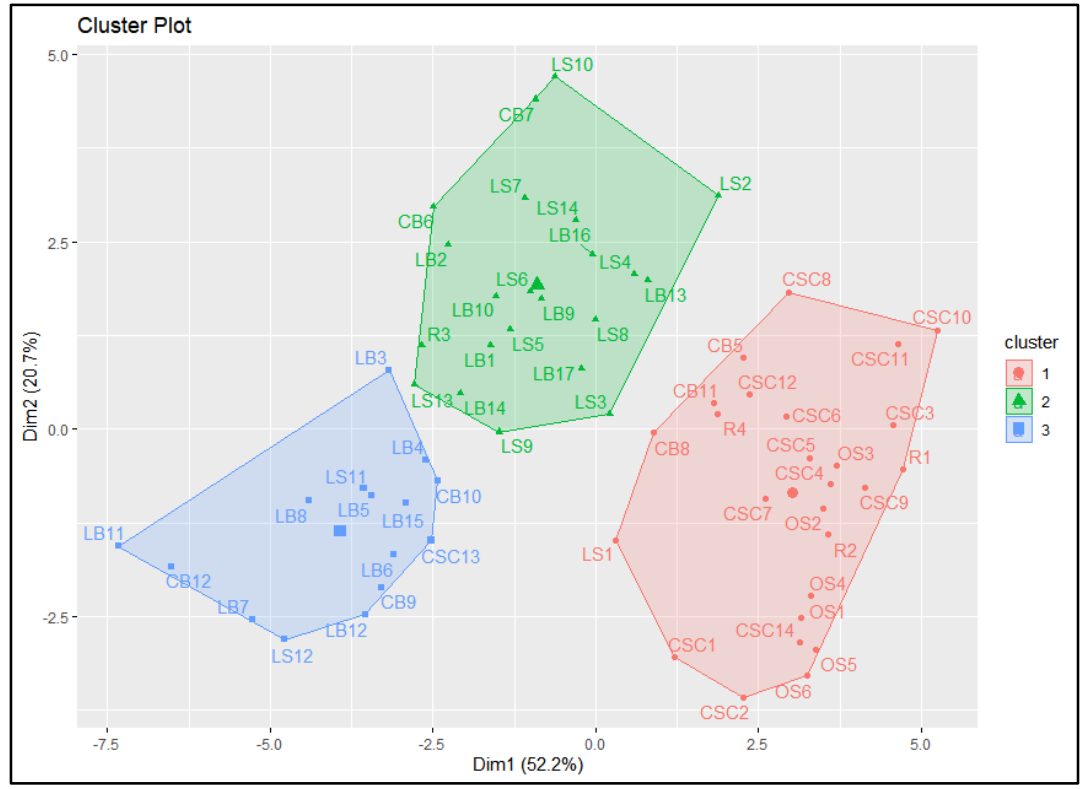

Figure 3. Result of the K-Means cluster analysis with $\mathrm{k}=3$. As with the PCA, clusters separate along the first PC (Dim1) and shows that Cluster 1 (primarily offshore, river, and channel sediments) are distinct from the other two clusters (primarily lake bed, lake shoreline, and CSC bank sediments).

\section{Table 2. K-Means cluster analysis sums of squares} (SS).

\begin{tabular}{|c|c|c|}
\hline Cluster & N observations & Within SS \\
\hline $\mathbf{1}$ & 15 & 108.1 \\
\hline $\mathbf{2}$ & 26 & 208.9 \\
\hline $\mathbf{3}$ & 22 & 175.7 \\
\hline Between SS & TOTAL SS & Var. Expl. \\
(BTSS) & (TSS) & (BTSS/TSS) \\
\hline 623.3 & 1116.0 & $\mathbf{5 5 . 8 \%}$ \\
\hline
\end{tabular}


Stable Isotope Analysis. The $\delta^{13} \mathrm{C}$ values of organic carbon associated with sediment can be used to distinguish terrestrial from marine provenance (Faure 1986). Thus, the $\delta^{13} \mathrm{C}$ isotope results were evaluated to determine if samples within Cluster 1 could further be distinguished based on marine versus terrestrial carbon signature. As shown in Figure 4, samples from river locations tend to be more depleted in $\delta^{13} \mathrm{C}(-27.5 \%$ to $-25.7 \%$ ), which is indicative of terrestrial $\mathrm{C} 3$ plant-sourced organic material (Pilson 1998; Hoefs 2009). Conversely, samples from the offshore locations are less depleted, having an organic carbon signature more typical of a marine phytoplankton source, which has an average $\delta^{13} \mathrm{C}$ value of approximately -22\% (Faure 1986; Pilson 1998). Between these ends, samples collected from the CSC demonstrate a gradient in $\delta^{13} \mathrm{C}$ values from marine to terrestrial that largely corresponds with upstream distance, as indicated by the lower-to-higher sequential numbering of the CSC samples (Figure 4). Of additional note is the relatively large shift $(0.7 \%)$ in $\delta^{13} \mathrm{C}$ values that occurs between CSC4 (-24.1\%o) and CSC $5(-24.8 \%)$. This depletion occurs over a distance of approximately 2 river miles and indicates a stronger terrestrial carbon signature at CSC 5, which is located at the intersection of the shipping channel and the GIWW (Figure 1). These isotope data, therefore, suggest a mixing between terrestrial and marine sediment sources with a reduction in marine sourced carbon upstream of the GIWW. A similarly observed gradient in $\delta^{15} \mathrm{~N}$ values was also consistent with terrestrial (lower) to marine (higher) signatures; $\delta^{15} \mathrm{~N}$ values of marine sediments are reported to range from +7 to $+12 \%$ (Faure 1986).

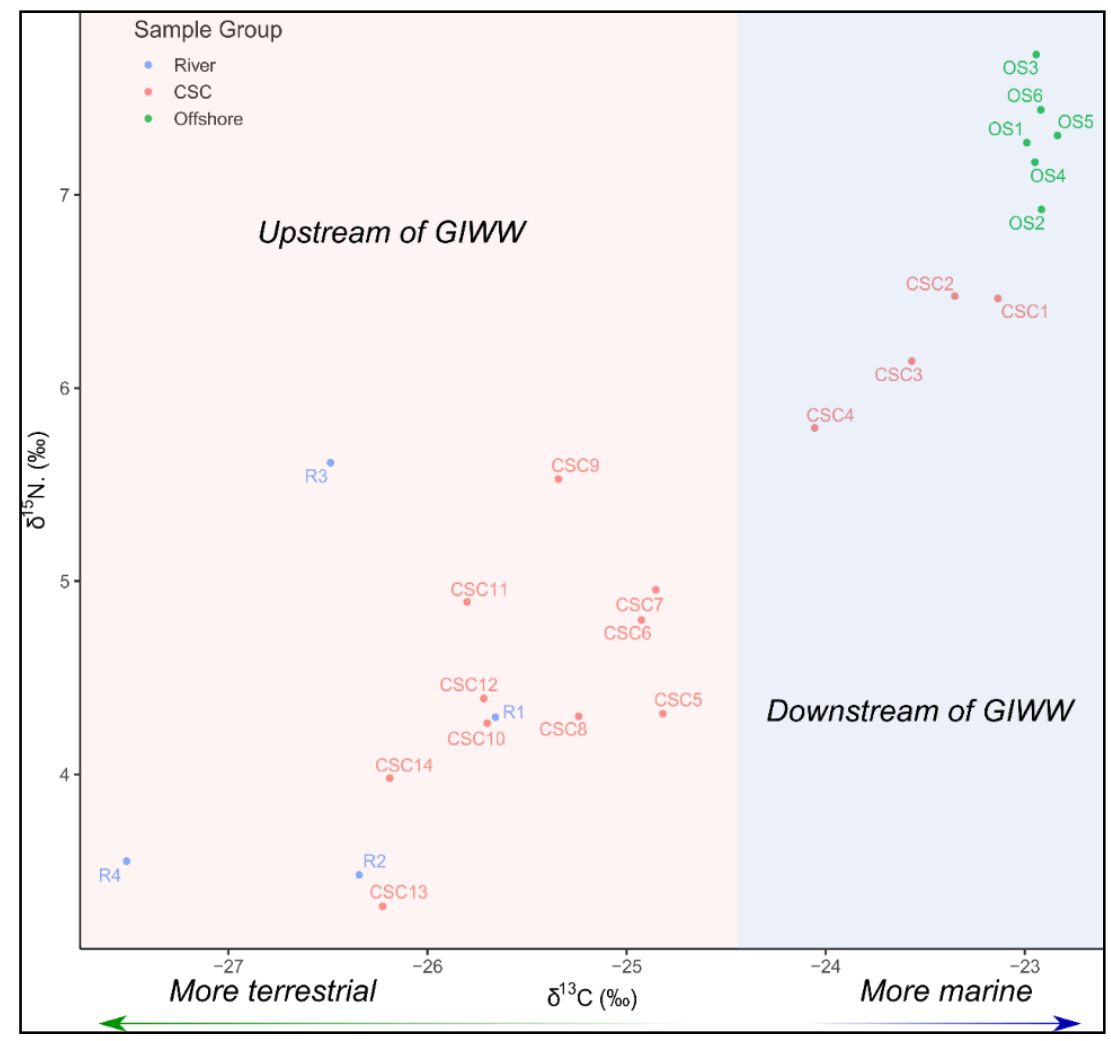

Figure 4. Trend of isotopic signatures derived from organic carbon and nitrogen showing the transition from terrestrial to marine values of samples from within the CSC. 
DISCUSSION: A working hypothesis of this study was that the adjacent marshes of Lake Calcasieu are significant sources of sediment to the CSC, as also postulated by Brown* . However, results from the statistical and geochemical analyses demonstrate that infilled CSC sediments are geochemically more similar to riverine and marine sediments rather than lake bed or marsh sediments. While eroded wetland sediments may contribute a significant amount of material to the Calcasieu system, transport to the CSC may be limited. This suggests that Lake Calcasieu may act as a local sink rather than a local source, supported by estimates of average sedimentation rates from ${ }^{210} \mathrm{~Pb}$ and ${ }^{137} \mathrm{Cs}$ geochronologies (WIG 2019).

The geochemical data supports the model results of Brown* in that a significant amount of sediment originates from an offshore source. Further, the stable carbon isotope data indicate that the marine carbon signature declines upstream and shifts to a stronger terrestrial $\mathrm{C} 3$ signature above RM 22 (GIWW). This observation also supports Brown's* numerical modeling results from the AdH model system, which suggested limited marine sediment transport upstream of the GIWW. The WIG (2019) study likewise identified a marine sediment flux, but the results varied in terms of a net source or sink due to tropical storm events during their monitoring.

According to Fischenich ${ }^{\dagger}$ (as reported in Brown*), CSC bankline erosion also yields a significant amount of sediment to the system (approximately 14\% of the dredge volume), mostly downstream of the GIWW. However, channel bank samples are geochemically variable and cannot be uniquely identified. Similarly, while this methodology provides insight into delineating various sediment sources, it cannot clearly identify alternative sources to balance unaccounted dredge volumes.

Further Research Recommendations. Sediments that are unaccounted for require alternative sources yet to be identified or quantified. Hypothesized sources include the GIWW, and the subaqueous portions of the CSC due to slow-moving lateral creep, which may be induced by plastic deformation after channel deepening (WIG 2019). The contribution of the GIWW (or other proposed sources) to CSC infilling can be tested by conducting another robust sediment collection effort and applying the analysis methods used here, while morphometric analyses from repeat, high-resolution bathymetric surveys may identify the nature and timing of infilling. However, resolving small changes between bathymetric datasets in the presence of fluid mud in the channel will produce larger uncertainties in calculated volume differences. Alternatively, the geotechnical properties and geochemical signatures of the lower portions of the CSC sidewalls could be compared to those of adjacent dredge material disposal areas.

Note that any future data collected for the intent of expanding the existing data set must be analyzed following the laboratory techniques and methods outlined in this report.

\section{CONCLUSIONS}

1. Multivariate statistical analysis was able to provide geochemical signatures for the types of sediment sources investigated.

\footnotetext{
* Brown, Gary. In preparation. Investigation of Sources of Sediment Associated with Deposition in the Calcasieu Ship Channel. FY18 RSM project report for US Army Engineer District, New Orleans.

${ }^{\dagger}$ Fischenich, Craig G. Unpublished. Calcasieu River and Ship Channel Erosion and Sediment Impact Assessment (Phase 1). DRAFT report prepared for the US Army Corps of Engineers, New Orleans District.
} 
2. A two-principle component model accounted for $73 \%$ of the variance in the geochemical data set, and a K-Means cluster analysis showed that these data could be best categorized into three unique groupings.

3. Groupings show that samples from within the CSC (inshore to offshore) tend to cluster while samples from the lake (bottom and shore) and CSC bank lines are mixed to form two other clusters.

4. Brown's* previously conducted sediment budget suggested that wetland erosion from lake and surrounding waters might be a significant source to CSC infilling ( $40 \%)$. However, data from this study along with WIG investigation indicate that sediments sourced from the lake edge and bottom are not likely to be a major source for deposited sediments in the CSC.

5. Stable carbon isotope data indicate that sediments within the offshore channel bar do have a clear marine carbon signature. A mixture of marine and terrestrial carbon was observed within the lower CSC indicating a significant amount of incoming sediments from offshore. The $\delta^{13} \mathrm{C}$ values indicated limited marine sourced sediments upstream of the GIWW. These $\delta^{13} \mathrm{C}$ results indicate a limit of offshore sediment influx that aligns with previous $\mathrm{AdH}$ modeling conducted by Brown*

6. These results, combined with those of previous studies, suggest that high cost mitigation practices such as isolating the lake or armoring its shores may not significantly reduce deposition within the navigation channel.

ADDITIONAL INFORMATION: This RSM-TN was prepared by David Perkey, Dr. Anthony Priestas, Dr. Brandon Boyd, Jeff Corbino, and Dr. Lee Moores. The study was conducted as an activity of the RSM Program, a Navigation Research, Development, and Technology portfolio program administered by Headquarters, USACE. For information on the RSM Program, please consult http://rsm.usace.army.mil or contact the Program Manager, Dr. Katherine E. Brutsché, Katherine.E.Brutsche@usace.army.mil. For information regarding this RSM-TN, please contact Mathew Schrader, Mathew.H.Schrader@usace.army.mil.

This technical note should be cited as follows:

Perkey, D., A. M. Priestas, B. Boyd, J. Corbino, and L. Moores. 2020. Geochemical Fingerprinting of Sediment Sources Associated with Deposition in the Calcasieu Ship Channel (CSC). ERDC/TN RSM-20-5. Vicksburg, MS: US Army Engineer Research and Development Center. http://dx.doi.org/10.21079/11681/36313

\section{REFERENCES}

ASTM (ASTM International) D2974-14. 2014. Standard Test Methods for Moisture, Ash, and Organic Matter of Peat and Other Organic Soils. West Conshohocken, PA: ASTM International.

Collins, A. L., and D. E. Walling. 2002. "Selecting Fingerprint Properties for Discriminating Potential Suspended Sediment Sources in River Basins." Journal of Hydrology 261(1): 218-244.

Collins, A. L., D. E. Walling, L. Webb, and P. King. 2010. "Apportioning Catchment Scale Sediment Sources Using a Modified Composite Fingerprinting Technique Incorporating Property Weightings and Prior Information." Geoderma 155(3): 249-261.

${ }^{*}$ Brown, Gary. In preparation. Investigation of Sources of Sediment Associated with Deposition in the Calcasieu Ship Channel. FY18 RSM project report for US Army Engineer District, New Orleans. 
Everitt, B. S. 2005. An R and S-Plus Companion to Multivariate Analysis. London: Springer-Verlag.

Faure, G. 1986. Principles of Isotope Geology. New York: John Wiley and Sons.

Gireeshkumar, T. R., P. M. Deepulal, and N. Chandramohanakumar. 2013. "Distribution and Sources of Sedimentary Organic Matter in a Tropical Estuary, Southwest Coast of India (Chochin estuary): A Baseline Study." Marine Pollution Bulletin 66(1-2): 239-245.

Hoefs, J. 2009. Stable Isotope Geochemistry. 6th ed. Berlin: Springer-Verlag.

Johnson, R. A., and D. W. Wichern. 2007. Applied Multivariate Statistical Analysis. 6th ed. New Jersey: Pearson Prentice Hall.

Kassambara, A., and F. Mundt. 2017. Facotextra: Extract and Visualize the Results of Multivariate Data Analyses. R package version 1.0.5. https://CRAN.R-project.org/package=factoextra

King, J. R., and D. A. Jackson. 1999. "Variable Selection in Large Environmental Data Sets Using Principal Components Analysis." Journal of Environmetrics 10: 67-77.

Mehlich, A. 1984. "Mehlich 3 Soil Test Extractant: A Modification of Mehlich 2 Extractant." Communications in Soil Science and Plant Analysis 15(12): 1409-1416.

Papanicolaou, A. N., J. F. Fox, and J. Marshall. 2003. "Soil Fingerprinting in the Palouse Basin, USA, Using Stable Carbon and Nitrogen Isotopes." International Journal of Sediment Research 18(2): 278-284.

Perkey, D. W., M. A. Chappell, J. M. Seiter, and H. M. Wadman. 2017. Identification of Sediment Sources to Calumet River through Geochemical Fingerprinting. ERDC TR-17-1. Vicksburg, MS: US Army Engineer Research and Development Center.

Pilson, M. E. Q. 1998. An Introduction to the Chemistry of the Sea. New Jersey: Prentice Hall.

R Core Team. 2019. R: A Language and Environment for Statistical Computing. R Foundation for Statistical Computing, Vienna, Austria. https://www.R-project.org/

Salehi, M. H., O. H. Beni, H. B. Harchegani, I. E. Borujeni, and H. R. Motaghian. 2011. "Refining Soil Organic Matter Determination by Loss-On-Ignition." Pedosphere 21(4): 473-482.

Schumaker, B. A. 2002. Methods for the Determination of Total Organic Carbon (TOC) in Soils and Sediments. Las Vegas, NV. US Environmental Protection Agency. Environmental Sciences Division, National Exposure Research Laboratory.

Thermo Fisher Scientific Niton Analyzers. 2010. XL3 Analyzer Version 7.0.1 User's Guide Version C.

WIG (The Water Institute of the Gulf). 2019. "Identifying Sediment Sources and Optimizing Placement of Dredge Material to Protect Critical Infrastructure - Port of Lake Charles." The Water Institute of the Gulf. Prepared for and funded by the Port of Lake Charles. Baton Rouge, LA.

NOTE: The contents of this technical note are not to be used for advertising, publication, or promotional purposes.

Citation of trade names does not constitute an official endorsement or approval of the use of such products. 